\title{
LIMITING STRUCTURES FOR SEQUENCES OF LINEAR FRACTIONAL TRANSFORMATIONS
}

\author{
LISA JACOBSEN AND W. J. THRON
}

\begin{abstract}
We introduce restrained sequences of linear fractional transformations which constitute an extension of the class of continued fractions which are generally convergent. The latter concept was recently introduced by L. Jacobsen. Even for elements of the larger class, a well-defined limiting structure exists (even though such sequences need not converge). Exceptional sequences $\left\{w_{n}\right\}$ for which $\left\{T_{n}\left(w_{n}\right)\right\}$ does not have the limiting structure associated with the sequence $\left\{T_{n}\right\}$ are also studied.
\end{abstract}

1. Introduction. Recall that continued fractions can be defined by a sequence $\left\{S_{n}\right\}$ of nonsingular linear fractional transformations as follows:

$$
S_{1}(w)=s_{1}(w), \quad S_{n}(w)=S_{n-1}\left(s_{n}(w)\right)
$$

where

$$
s_{n}(w)=\frac{a_{n}}{b_{n}+w}, \quad a_{n} \neq 0, n \geq 1 .
$$

According to the classical definition a continued fraction is called convergent if $\left\{S_{n}(0)\right\}$, its sequence of approximants, converges in $\hat{\mathbf{C}}$.

There have been a number of investigations over the years with the purpose of finding a definition for convergence which did not rely solely on the behavior of $\left\{S_{n}\right\}$ at $w=0$ (see $[3]$ ). With growing interest in sequences of modified approximants $\left\{S_{n}\left(w_{n}\right)\right\}$, redefining convergence became even more urgent.

The aim is to have a formulation which, for as large a class of sequences $\left\{S_{n}\right\}$ as possible, assigns a well-defined limiting value to the sequence. A definition meeting this requirement to some extent was proposed in [3]. It required that there be two distinct points $u, v$ in $\hat{\mathbf{C}}$ for which

$$
\lim _{n \rightarrow \infty} S_{n}(u)=\lim _{n \rightarrow \infty} S_{n}(v) .
$$

There was also an additional condition insuring a certain degree of uniform convergence for sequences $\left\{S_{n}\left(w_{n}\right)\right\}$. Since one is definitely interested in more general $\left\{S_{n}\left(w_{n}\right)\right\}$ it would have been desirable to state the requirement (1.1) in terms of sequences $\left\{u_{n}\right\}$; that is points in $\hat{\mathbf{C}}^{\infty}$. That this was not done was due, in large part, to the bothersome fact that given any sequence $\left\{S_{n}\right\}$ and a value $w \in \hat{\mathbf{C}}$ one can always find a sequence $\left\{z_{n}\right\}$ so that $\lim S_{n}\left(z_{n}\right)=w$. One possible choice is $z_{n}=S^{-1}(w)$. It thus seened unlikely that one would be able to assign a unique

Received by the editors July 12, 1985 and, in revised form, December 11, 1985.

1980 Mathematics Subject Classification (1985 Revision). Primary 40A99; Secondary 40A15, $30 \mathrm{~B} 70$.

The second author's research was supported in part by the U.S. National Science Foundation under Grant No. DMS 8401717. 
limit if one allowed a modification of $(1.1)$ in terms of distinct points in $\hat{\mathbf{C}}^{\infty}$; that is

$$
\lim _{n \rightarrow \infty} S_{n}\left(u_{n}\right)=\lim _{n \rightarrow \infty} S_{n}\left(v_{n}\right)
$$

In her recent paper [2] Jacobsen was able to show that this fear was not justified since the sequences $\left\{z_{n}\right\}$, considered above, are exceptional in a manner which one can pin down precisely. She was thus led to define general convergence. Another important ingredient in the definition was the use of chordal distance (see $[\mathbf{1}, \mathrm{p}$. 81])

$$
d(u, v)=-\frac{|u-v|}{\sqrt{1+|u|^{2}} \sqrt{1+|v|^{2}}}, \quad d(u, \infty)=\frac{1}{\sqrt{1+|u|^{2}}} .
$$

Two sequences $\left\{u_{n}\right\},\left\{v_{n}\right\}$ shall be considered distinct if

$$
\liminf _{n \rightarrow \infty} d\left(u_{n}, v_{n}\right)>0 .
$$

A continued fraction is then said to be generally convergent if there exists a pair of sequences $\left\{u_{n}\right\},\left\{v_{n}\right\}$ for which (1.3) and (1.2) hold.

In this article we shall show that there is a larger class of sequences for which most of the properties of generally convergent sequences $\left\{S_{n}\right\}$ are still valid. This enlargement can be carried out in two directions. First, instead of considering only continued fraction generating sequences $\left\{S_{n}\right\}$ we study arbitrary sequences $\left\{T_{n}\right\}$ of nonsingular linear fractional transformations. Secondly, instead of demanding that for two sequences $\left\{u_{n}\right\},\left\{v_{n}\right\}$ satisfying (1.3) the condition (1.2) be satisfied, we replace $(1.2)$ by the weaker requirement

$$
\lim _{n \rightarrow \infty} d\left(T_{n}\left(u_{n}\right), T_{n}\left(v_{n}\right)\right)=0 .
$$

Thus the sequences $\left\{T_{n}\left(u_{n}\right)\right\},\left\{T_{n}\left(v_{n}\right)\right\}$ need not converge. All we require is that they have the same limiting structure, which is defined below.

DEFINITION 1.1. Two sequences $\left\{w_{n}\right\},\left\{z_{n}\right\}$ are said to have the same limiting structure if

$$
\lim _{n \rightarrow \infty} d\left(w_{n}, z_{n}\right)=0
$$

The two sequences are said to have distinct limiting structures if

$$
\limsup _{n \rightarrow \infty} d\left(w_{n}, z_{n}\right)>0 .
$$

Note that if two sequences have the same limiting structure, then they have the same limit points. The converse however is not in general true since the order of the elements is critical in Definition 1.1.

We are now ready to define the sequences which we are about to study.

DEFINITION 1.2. A sequence $\left\{T_{n}\right\}$ of nonsingular linear fractional transformations shall be called a restrained sequence if there exists a pair of sequences $\left\{u_{n}\right\}$, $\left\{v_{n}\right\}$ which satisfies (1.3) and is such that the sequences $\left\{T_{n}\left(u_{n}\right)\right\},\left\{T_{n}\left(v_{n}\right)\right\}$ have the same limiting structure (that is they satisfy (1.4)).

The main tool in our investigation is the invariance of the crossratio of four complex numbers under a nonsingular linear fractional transformation. If $u_{n}, v_{n}, w_{n}, z_{n}$ are distinct points in $\hat{\mathbf{C}}$, then

$$
\frac{\left(T_{n}\left(u_{n}\right)-T_{n}\left(w_{n}\right)\right)\left(T_{n}\left(v_{n}\right)-T_{n}\left(z_{n}\right)\right)}{\left(T_{n}\left(u_{n}\right)-T_{n}\left(v_{n}\right)\right)\left(T_{n}\left(w_{n}\right)-T_{n}\left(z_{n}\right)\right)}=\frac{\left(u_{n}-w_{n}\right)\left(v_{n}-z_{n}\right)}{\left(u_{n}-v_{n}\right)\left(w_{n}-z_{n}\right)}
$$


Moreover

$$
\left|\frac{\left(u_{n}-w_{n}\right)\left(v_{n}-z_{n}\right)}{\left(u_{n}-v_{n}\right)\left(w_{n}-z_{n}\right)}\right|=\frac{d\left(u_{n}, w_{n}\right) d\left(v_{n}, z_{n}\right)}{d\left(u_{n}, v_{n}\right) d\left(w_{n}, z_{n}\right)} .
$$

Combining these two results one arrives at

$$
\frac{d\left(T_{n}\left(u_{n}\right), T_{n}\left(w_{n}\right)\right) d\left(T_{n}\left(v_{n}\right), T_{n}\left(z_{n}\right)\right)}{d\left(T_{n}\left(u_{n}\right), T_{n}\left(v_{n}\right)\right) d\left(T_{n}\left(w_{n}\right), T_{n}\left(z_{n}\right)\right)}=\frac{d\left(u_{n}, w_{n}\right) d\left(v_{n}, z_{n}\right)}{d\left(u_{n}, v_{n}\right) d\left(w_{n}, z_{n}\right)}
$$

We conclude this introductory section by recalling that

$$
d(u, v) \leq 1 \quad \text { for all } u, v \in \hat{\mathbf{C}} .
$$

2. Limiting structures of restrained sequences. One can now establish the following basic result.

THEOREM 2.1. If $\left\{T_{n}\right\}$ is a restrained sequence with respect to two pairs of sequences $\left\{u_{n}\right\},\left\{v_{n}\right\}$ and $\left\{u_{n}^{\prime}\right\},\left\{v_{n}^{\prime}\right\}$, then $\left\{T_{n}\left(u_{n}\right)\right\}$ and $\left\{T_{n}\left(u_{n}^{\prime}\right)\right\}$ have the same limiting structure.

REMARKS. We see that the limiting structure of a restrained sequence is uniquely determined. From now on $\left\{u_{n}\right\}$ shall always be assumed to be one of a pair of sequences with respect to which $\left\{T_{n}\right\}$ is restrained. Thus the limiting structure of a restrained sequence is given by $\left\{T_{n}\left(u_{n}\right)\right\}$.

PROOF OF THEOREM 2.1. If $u_{n}=u_{n}^{\prime}$ or $v_{n}=v_{n}^{\prime}$ or $u_{n}=v_{n}^{\prime}$ or $v_{n}=u_{n}^{\prime}$, then for any subsequence for which one of these equalities holds the conclusion of the theorem follows immediately. It remains to consider the situation when $u_{n}, v_{n}, u_{n}^{\prime}, v_{n}^{\prime}$ are distinct. Then formula (1.7) can be used if one sets $w_{n}=u_{n}^{\prime}, z_{n}=$ $v_{n}^{\prime}$. It follows from the assumptions of the theorem and the fact that $d\left(u_{n}, u_{n}^{\prime}\right)<$ $1, d\left(v_{n}, v_{n}^{\prime}\right)<1$ that the right-hand side of $(1.7)$ is bounded. Hence

$$
\lim _{n \rightarrow \infty} d\left(T_{n}\left(u_{n}\right), T_{n}\left(u_{n}^{\prime}\right)\right) d\left(T_{n}\left(v_{n}\right), T_{n}\left(v_{n}^{\prime}\right)\right)=0 .
$$

From the triangle inequality

$$
d\left(T_{n}\left(u_{n}\right), T_{n}\left(u_{n}^{\prime}\right)\right)<d\left(T_{n}\left(u_{n}\right), T_{n}\left(v_{n}\right)\right)+d\left(T_{n}\left(v_{n}\right), T_{n}\left(v_{n}^{\prime}\right)\right)+d\left(T_{n}\left(v_{n}^{\prime}\right), T_{n}\left(u_{n}^{\prime}\right)\right),
$$

and the analogous inequality for $d\left(T_{n}\left(v_{n}\right), T_{n}\left(v_{n}^{\prime}\right)\right)$, one concludes that

$$
d\left(T_{n}\left(u_{n}\right), T_{n}\left(u_{n}^{\prime}\right)\right)=d\left(T_{n}\left(v_{n}\right), T_{n}\left(v_{n}^{\prime}\right)\right)+\varepsilon_{n},
$$

where $\varepsilon_{n} \rightarrow 0$. It then follows from (2.1) that

$$
\lim _{n \rightarrow \infty} d\left(T_{n}\left(u_{n}\right), T_{n}\left(u_{n}^{\prime}\right)\right)=0 .
$$

For a restrained sequence $\left\{T_{n}\right\}$ we define exceptional sequences as follows.

DEFINITION 2.1. A sequence $\left\{w_{n}\right\}$ is said to be exceptional (strongly exceptional) with respect to a restrained sequence $\left\{T_{n}\right\}$ if

$$
\limsup _{n \rightarrow \infty} d\left(T_{n}\left(w_{n}\right), T_{n}\left(u_{n}\right)\right)>0 \quad\left(\liminf _{n \rightarrow \infty} d\left(T_{n}\left(w_{n}\right), T_{n}\left(u_{n}\right)\right)>0\right) .
$$

Here $\left\{u_{n}\right\}$ (see Remark after Theorem 2.1) is one of the sequences with respect to which $\left\{T_{n}\right\}$ is restrained. It follows from Theorem 2.1 that $\left\{w_{n}\right\}$ being exceptional depends only on $\left\{T_{n}\right\}$, not on the particular $\left\{u_{n}\right\}$ chosen. 
For exceptional sequences one can prove:

PROPOSITION 2.2. If $\left\{T_{n}\right\}$ is a restrained sequence, $\left\{w_{n}\right\}$ is an exceptional (strongly exceptional) sequence, and $\left\{z_{n}\right\}$ is strongly exceptional with respect to $\left\{T_{n}\right\}$, then

$$
\liminf _{n \rightarrow \infty} d\left(w_{n}, z_{n}\right)=0 \quad\left(\lim _{n \rightarrow \infty} d\left(w_{n}, z_{n}\right)=0\right) .
$$

PROOF. Either a subsequence (or the whole sequence) on the left-hand side of formula (1.7) approaches $\infty$. From this the result follows.

PROPOSITION 2.3. If $\left\{T_{n}\right\}$ is a restrained sequence, one can always find a pair of strongly exceptional sequences $\left\{w_{n}\right\},\left\{z_{n}\right\}$ for which, in addition to

one has

$$
\lim _{n \rightarrow \infty} d\left(w_{n}, z_{n}\right)=0
$$

$$
\liminf _{n \rightarrow \infty} d\left(T_{n}\left(w_{n}\right), T_{n}\left(z_{n}\right)\right)>0 .
$$

ProOF. Consider the great circle on the Riemann sphere passing through the images of $T_{n}\left(u_{n}\right), T_{n}\left(v_{n}\right)$. Let $M_{n}$ be the midpoint on the shorter arc between these two points. Now locate $A_{n}$ and $B_{n}$ on the great circle in such a way that $A_{n}, B_{n}, M_{n}$ are the vertices of an equilateral triangle. Set $w_{n}=T_{n}^{-1}\left(A_{n}\right), z_{n}=T_{n}^{-1}\left(B_{n}\right)$. Then

and

$$
d\left(T_{n}\left(w_{n}\right), T_{n}\left(z_{n}\right)\right)=\sqrt{3} / 2
$$

$$
\lim _{n \rightarrow \infty} d\left(T_{n}\left(w_{n}\right), T_{n}\left(u_{n}\right)\right)=\sqrt{3} / 2, \quad \lim _{n \rightarrow \infty} d\left(T_{n}\left(z_{n}\right), T_{n}\left(u_{n}\right)\right)=\sqrt{3} / 2
$$

so that $\left\{w_{n}\right\}$ and $\left\{z_{n}\right\}$ are strongly exceptional with respect to $\left\{T_{n}\right\}$ from which $\lim d\left(w_{n}, z_{n}\right)=0$ follows.

Tail sequences $\left\{z_{n}\right\}$ of $\left\{T_{n}\right\}$, that is $z_{n}=T_{n}^{-1}(w)$, frequently are exceptional sequences. They are strongly exceptional if $w$ is not a limit point of the sequence $\left\{T_{n}\left(u_{n}\right)\right\}$. Thus for $\left\{-h_{n}\right\}$, where

$$
-h_{n}=T_{n}^{-1}(\infty)
$$

we have the following result.

PROPOSITION 2.4. If $\left\{T_{n}\right\}$ is a restrained sequence and $\lim \sup T_{n}\left(u_{n}\right)<\infty$, then for an exceptional (strongly exceptional) sequence $\left\{w_{n}\right\}$ one has

$$
\liminf _{n \rightarrow \infty} d\left(w_{n},-h_{n}\right)=0 \quad\left(\lim _{n \rightarrow \infty} d\left(w_{n},-h_{n}\right)=0\right) .
$$

PROOF. $d\left(T_{n}\left(u_{n}\right), T_{n}\left(-h_{n}\right)\right)=d\left(T_{n}\left(u_{n}\right), \infty\right)=1 / \sqrt{1+\left|T_{n}\left(u_{n}\right)\right|^{2}}>d$ so that $\left\{-h_{n}\right\}$ is strongly exceptional. Hence the theorem follows from Theorem 2.2.

That for "most" sequences $\left\{t_{n}\right\}$ the sequence $\left\{T_{n}\left(t_{n}\right)\right\}$ has the same limiting structure as $\left\{T_{n}\left(u_{n}\right)\right\}$ is a consequence of our next result.

THEOREM 2.5. Let $\left\{T_{n}\right\}$ be a restrained sequence and let $\left\{z_{n}\right\}$ be a strongly exceptional sequence with respect to $\left\{T_{n}\right\}$. Let $\left\{t_{n}\right\}$ be any sequence satisfying $\liminf _{n \rightarrow \infty} d\left(z_{n}, t_{n}\right)>0$. Then

$$
\lim _{n \rightarrow \infty} d\left(T_{n}\left(t_{n}\right), T_{n}\left(u_{n}\right)\right)=0 .
$$


ProOF. Assume that $\left\{t_{n}\right\}$ is exceptional. Then using Theorem 2.2 one can conclude that liminf $d\left(z_{n}, t_{n}\right)=0$ which contradicts the assumption of this theorem. It follows that

$$
\lim d\left(T_{n}\left(t_{n}\right), T_{n}\left(u_{n}\right)\right)=0 .
$$

A rather surprising result is the following.

THEOREM 2.6. If $\left\{T_{n}\right\}$ is a restrained sequence, then $\left\{T_{n}^{-1}\right\}$ is a restrained sequence.

PROOF. It follows from Theorem 2.3 that there exist sequences $\left\{w_{n}\right\},\left\{z_{n}\right\}$ which satisfy $\lim d\left(w_{n}, z_{n}\right)=0$ and $\liminf d\left(T_{n}\left(w_{n}\right), T_{n}\left(z_{n}\right)\right)>0$. Set $U_{n}=T_{n}\left(w_{n}\right)$, $V_{n}=T_{n}\left(z_{n}\right)$, so that $w_{n}=T_{n}^{-1}\left(U_{n}\right), z_{n}=T_{n}^{-1}\left(V_{n}\right)$. Then $\liminf d\left(U_{n}, V_{n}\right)>0$ and $\lim d\left(T_{n}^{-1}\left(U_{n}\right), T_{n}^{-1}\left(V_{n}\right)\right)=0$. It follows that $\left\{T_{n}^{-1}\right\}$ is restrained.

An interesting sufficient condition for a sequence $\left\{T_{n}\right\}$ to be restrained can now be proved.

PROPOSITION 2.7. If there exists a pair of sequences $\left\{t_{n}\right\},\left\{s_{n}\right\}$ for which $\lim d\left(t_{n}, s_{n}\right)=0$ and $\liminf d\left(T_{n}\left(t_{n}\right), T_{n}\left(s_{n}\right)\right)>0$, then $\left\{T_{n}\right\}$ is a restrained sequence.

PROOF. We have seen in the proof of the previous theorem that the assumptions of this theorem are sufficient to insure that $\left\{T_{n}^{-1}\right\}$ is restrained. Hence by Theorem $2.6\left\{T_{n}\right\}$ is restrained.

In the next section the result below will be useful.

PROPOSITION 2.8. If $\left\{T_{n}\right\}$ is a restrained sequence, then there exist sequences $\left\{u_{n}\right\},\left\{v_{n}\right\}$ satisfying

$$
\liminf d\left(u_{n},-h_{n}\right)>0, \quad \liminf d\left(v_{n},-h_{n}\right)>0,
$$

and

$$
\lim d\left(T_{n}\left(u_{n}\right), T_{n}\left(v_{n}\right)\right)=0 .
$$

Here $-h_{n}$ is the quantity defined in (2.2).

PROOF. Let $\left\{z_{n}\right\}$ be exceptional with respect to $\left\{T_{n}\right\}$. On the great circle of the Riemann sphere passing through the images of $-h_{n}$ and $z_{n}$ place the images of $u_{n}$ and $v_{n}$ on the larger of the two arcs with endpoints at the images of $-h_{n}, z_{n}$ in such a way that the arc is split into three equal subarcs. It follows that the first three conditions are satisfied. The last condition follows from Theorem 2.5.

3. Restraint in terms of parameters. Every linear fractional transformation can be written as

$$
T_{n}(w)= \begin{cases}c_{n}+\varepsilon_{n} /\left(w+h_{n}\right) & \text { if } h_{n} \neq \infty \\ \varepsilon_{n} w+d_{n} & \text { if } h_{n}=\infty\end{cases}
$$

We propose to investigate, in terms of the parameters $\varepsilon_{n}, h_{n}, c_{n}$, and $d_{n}$, when $\left\{T_{n}\right\}$ is a restrained sequence. Unfortunately, we cannot achieve the generality of results in this section which we were able to obtain in the previous section. This is largely due to the fact that in expressing $T_{n}(w)$, two cases seem to be unavoidable. One can also write

$$
T_{n}(w)= \begin{cases}d_{n}+\varepsilon_{n} h_{n} w /\left(w+h_{n}\right) & \text { if } h_{n} \neq 0 \\ c_{n}+\varepsilon_{n} / w & \text { if } h_{n}=0\end{cases}
$$


In both expressions we have set $T_{n}(\infty)=c_{n}, T_{n}(0)=d_{n}$. From (3.1) one obtains

$$
\left|T_{n}\left(u_{n}\right)-T_{n}\left(v_{n}\right)\right|= \begin{cases}\left|\varepsilon_{n}\right|\left|u_{n}-v_{n}\right| /\left|u_{n}+h_{n}\right| \cdot\left|v_{n}+h_{n}\right| & \text { if } h_{n} \neq \infty \\ \left|\varepsilon_{n}\right|\left|u_{n}-v_{n}\right| & \text { if } h_{n}=\infty\end{cases}
$$

Hence

$$
\begin{aligned}
d\left(T_{n}\left(u_{n}\right),\right. & \left.T_{n}\left(v_{n}\right)\right) \sqrt{\left(1+\left|T_{n}\left(u_{n}\right)\right|^{2}\right)\left(1+\left|T_{n}\left(v_{n}\right)\right|^{2}\right)} \\
& = \begin{cases}\left|\varepsilon_{n}\right| d\left(u_{n}, v_{n}\right) / d\left(u_{n},-h_{n}\right) d\left(v_{n},-h_{n}\right)\left(1+\left|h_{n}\right|^{2}\right) & \text { if } h_{n} \neq \infty, \\
\left|\varepsilon_{n}\right| d\left(u_{n}, v_{n}\right) / d\left(u_{n}, \infty\right) d\left(v_{n}, \infty\right) & \text { if } h_{n}=\infty\end{cases}
\end{aligned}
$$

If we choose $u_{n}, v_{n}$ so that

$$
d\left(u_{n}, v_{n}\right)=d\left(u_{n},-h_{n}\right)=d\left(v_{n},-h_{n}\right)=\sqrt{3} / 2
$$

(this can be done even for $h_{n}=\infty$ ), we obtain

$$
d\left(T_{n}\left(u_{n}\right), T_{n}\left(v_{n}\right)\right) \leq \begin{cases}2\left|\varepsilon_{n}\right| /\left(1+\left|h_{n}\right|^{2}\right) \sqrt{3} & \text { if } h_{n} \neq \infty \\ 2\left|\varepsilon_{n}\right| / \sqrt{3} & \text { if } h_{n}=\infty\end{cases}
$$

From this the following result can be derived.

THEOREM 3.1. For a sequence $\left\{T_{n}\right\}$ to be restrained, it suffices that either $\lim \varepsilon_{n}=0\left(\varepsilon_{n}\right.$ is defined in formula (3.1)), or $h_{n} \neq \infty$ and $\lim h_{n}=\infty$.

There are other conditions which insure that $\left\{T_{n}\right\}$ is restrained. For example, $\lim _{n \rightarrow \infty} c_{n}=\infty$, provided limsup $\left|\varepsilon_{n}\right|<\infty$, or

$$
\limsup _{n \rightarrow \infty}\left|c_{n}\right|<\infty, \quad \limsup _{n \rightarrow \infty}\left|h_{n}\right|<\infty, \quad \lim _{n \rightarrow \infty} \varepsilon_{n}=\infty .
$$

In addition, one can have "mixed" conditions where one subsequence satisfies one set of conditions, another satisfies another set, etc.

In view of this it is clear that it is difficult to state a simple necessary condition for $\left\{T_{n}\right\}$ to be restrained in terms of the parameters $\varepsilon_{n}, h_{n}, c_{n}$, and $d_{n}$.

\section{REFERENCES}

1. Constantin Carathéodory, Theory of functions of a complex variable, vol. 1, Chelsea, New York, 1954.

2. Lisa Jacobsen, General convergence of continued fractions, Trans. Amer. Math. Soc. 294 (1986), 477-485.

3. W. J. Thron and Haakon Waadeland, Modifications of continued fractions, a survey, Lecture Notes in Math., vol. 932, Springer-Verlag, Berlin and New York, 1982.

INSTitute of Mathematics and Statistics, UNiVERSity of Trondheim, AVH, N-7055 DRAGVOLL, NORWAY

Department of MAThematics, UniVersity of Colorado, Boulder, Colorado 80309-0426 